\title{
Interferon- $\gamma$ Induced Medulloblastoma in the Developing Cerebellum
}

\author{
Wensheng Lin, ${ }^{1}$ April Kemper, ${ }^{3}$ Ken D. McCarthy, ${ }^{4}$ Peter Pytel, ${ }^{2}$ Jian-Ping Wang, ${ }^{5}$ Iain L. Campbell, ${ }^{6}$ Manuel F. Utset, ${ }^{2}$ \\ and Brian Popko ${ }^{1}$ \\ ${ }^{1}$ Jack Miller Center for Peripheral Neuropathy, Department of Neurology, and ${ }^{2}$ Department of Pathology, University of Chicago, Chicago, Illinois 60637, \\ ${ }^{3}$ Neuroscience Center and ${ }^{4}$ Department of Pharmacology, University of North Carolina at Chapel Hill, Chapel Hill, North Carolina 27599, ${ }^{5}$ Division of \\ Pharmacology, University of Missouri-Kansas City, Kansas City, Missouri 64108, and ${ }^{6}$ School of Molecular and Microbial Biosciences, The University of \\ Sydney, Sydney, New South Wales 2006, Australia
}

We have generated a mouse model system with a high incidence of medulloblastoma, a malignant neoplasm believed to arise from immature precursors of cerebellar granule neurons. These animals ectopically express interferon- $\gamma$ (IFN- $\gamma$ ) in astrocytes in the CNS in a controlled manner, exploiting the tetracycline-controllable system. More than $80 \%$ of these mice display severe ataxia and develop cerebellar tumors that express synaptophysin, the mouse atonal homolog MATH1, sonic hedgehog (SHH), and Gli1. IFN- $\gamma$-induced tumorigenesis in these mice is associated with increased expression of $\mathrm{SHH}$, and $\mathrm{SHH}$ induction and tumorigenesis are dependent on signal transducer and activator of transcription 1 (STAT1). When IFN- $\gamma$ expression is shut down with doxycycline at postnatal day 12 (P12), the clinical symptoms dissipate and the mice do not develop tumors, whereas if transgene expression is shut down at P16, the clinical symptoms and tumors progress to lethality, indicating that IFN- $\gamma$ is required for tumor induction but not progression. The tumors that occur in the continued presence of IFN- $\gamma$ display extensive necrosis and apoptosis as well as macrophage and lymphocytic infiltration, whereas the tumors that develop in mice in which IFN- $\gamma$ expression is shut down at P16 do not. Thus, IFN- $\gamma$ expression in the perinatal period can induce SHH expression and medulloblastoma in the cerebellum by a STAT1-dependent mechanism, and its continued presence appears to promote a host response to the tumor.

Key words: interferon- $\gamma$; medulloblastoma; sonic hedgehog; signal transducer and activator of transcription; transgenic mice; neuroimmunomodulation; cerebellum

\section{Introduction}

Medulloblastoma is a highly malignant embryonal neoplasm of the cerebellum. It is the most common solid malignancy of childhood, with most tumors occurring between 5 and 10 years of age (Packer et al., 1994). In recent years, significant progress has been made in understanding the mechanisms underlying medulloblastoma development and in relating these mechanisms to the normal development of the cerebellum (Wechsler-Reya and Scott, 2001; Eberhart, 2003). Insights into specific genetic pathways altered in these tumors have been provided by two inherited disorders: Gorlin syndrome, characterized by medulloblastoma and multiple basal cell carcinomas of the skin, and Turcot syndrome, which is typified by the occurrence of a colorectal neoplasm and a primary brain tumor in the same patient. Gorlin

Received June 30, 2004; revised Sept. 28, 2004; accepted Sept. 28, 2004.

This work was supported by National Institutes of Health Grants NS34939 (B.P.) and MH62231 (I.L.C.), by National Multiple Sclerosis Society Grant RG 3291 A4/T (B.P.), and by grants from the Schweppe Foundation, the Brain Research Foundation, and the Children's Brain Tumor Foundation to M.F.U. We acknowledge the helpful contribution of discussions with colleagues at the Myelin Repair Foundation.

Correspondence should be addressed to either of the following: Dr. Brian Popko, Jack Miller Center for Peripheral Neuropathy, Department of Neurology, University of Chicago, 5841 South Maryland Avenue, MC2030, Chicago, IL 60637, E-mail: bpopko@neurology.bsd.uchicago.edu; or Dr. Manuel F. Utset, Department of Pathology, University of Chicago, 924 East 57th Street, Chicago, IL 60637, E-mail: m-utset@uchicago.edu.

D01:10.1523/JNEUROSCI.2604-04.2004

Copyright $\odot 2004$ Society for Neuroscience ～0270-6474/04/2410074-10\$15.00/0 syndrome is caused by germ-line mutations of the human homolog of the Drosophila segment polarity gene patched (PTCH), which encodes the receptor for sonic hedgehog $(\mathrm{SHH})$, and cases of Turcot syndrome in which the brain tumor is medulloblastoma caused by germ-line mutations of adenomatous polyposis coli, an important component of the wingless-type (Wnt) signaling pathway. These same signaling pathways are implicated in sporadic medulloblastomas, of which $\sim 25 \%$ have a mutation affecting the SHH pathway and $25 \%$ have mutations affecting the Wnt pathway.

Interferon- $\gamma($ IFN- $\gamma)$ is a pleiotropic cytokine secreted by activated T-lymphocytes and natural killer cells. IFN- $\gamma$ is involved in antiviral responses, immune surveillance, inhibiting cellular proliferation, and tumor suppression (Boehm et al., 1997; Ikeda et al., 2002; Ramana et al., 2002). Several lines of evidence suggest that IFN- $\gamma$ mediates an array of pathophysiological effects on the CNS (Popko et al., 1997; Popko and Baerwald, 1999; SredniKenigsbuch, 2002). Transgenic mice ectopically expressing IFN- $\gamma$ in the CNS show hypomyelination and abnormal proliferation, differentiation, and migration of cerebellar granule neurons (Corbin et al., 1996; LaFerla et al., 2000). More recently, it was shown that IFN- $\alpha$ production in the neonatal brain in the absence of signal transducer and activator of transcription 2 (STAT2) resulted in the abnormal proliferation of the external 
granular layer (EGL) and the development of medulloblastoma (Wang et al., 2003). This neoplastic phenotype was associated with the STAT1-dependent activation of the SHH signaling pathway in granule neurons, a process that was induced by IFN- $\gamma$ produced by $\mathrm{T}$-lymphocytes entering the brain in response to IFN- $\alpha$.

To better understand the effect of IFN- $\gamma$ on the CNS, we generated transgenic mice that allow for controlled delivery of IFN- $\gamma$ using the tetracycline-controllable system (Gao et al., 1999). To drive tetracycline-controlled transcriptional activator (tTA) expression, we chose the transcriptional regulatory region of the glial fibrillary acidic protein (GFAP) gene, which has been well characterized in transgenic studies (Brenner et al., 1994; Eng et al., 2000). We find that perinatal expression of IFN- $\gamma$ in the CNS greatly upregulates SHH expression in the developing cerebellum and leads to medulloblastoma. As the tumors progress, they become independent of continued IFN- $\gamma$ expression, which appears to induce host responses to the tumor. Furthermore, we demonstrate that the transcription factor STAT1 is required for the development of these tumors.

\section{Materials and Methods}

Generation of transgenic mice. A GFAP/LacZ construct containing $2.2 \mathrm{~kb}$ of the GFAP transcriptional control region and $3.1 \mathrm{~kb}$ of LacZ cDNA was obtained from Dr. Michael Brenner (University of Alabama at Birmingham, Birmingham, AL) (Brenner et al., 1994). The GFAP/LacZ construct was cut with $\mathrm{BamHI}$ to excise the $3.1 \mathrm{~kb} \mathrm{LacZ} \mathrm{cDNA}$, which was ligated to a $1.0 \mathrm{~kb} E c o \mathrm{RI} / \mathrm{Bam} \mathrm{HI}$ fragment containing the tTA cDNA isolated from $\mathrm{P}^{\text {TET-OFF }}$ (Clontech, Palo Alto, CA), creating the GFAP/tTA construct. The GFAP/tTA construct was digested with EcoRI to release a $4.0 \mathrm{~kb}$ fragment containing the transgene. The tetracycline responsive element (TRE)/lacZ/globin construct, which was obtained from Dr. H. Bujard (Universität Heidelberg, Heidelberg, Germany) (Furth et al., 1994), was cut with BamHI and XbaI to excise the LacZ cDNA. A $0.5 \mathrm{~kb} \mathrm{BamHI}$ fragment containing the mouse IFN- $\gamma$ cDNA was isolated from the MBP/IFN- $\gamma$ vector (Corbin et al., 1996) and subcloned into the TRE construct, creating the TRE/IFN- $\gamma$ construct. The TRE/IFN- $\gamma$ construct was digested with $\mathrm{XhoI}$ and AseI to release a $2.3 \mathrm{~kb}$ fragment containing the transgene. The transgene fragments were purified by agarose gel eletrophoresis and electroelution and injected into fertilized B6D2F1 mouse oocytes. Transgenic founder mice were identified by Southern blot analysis. After founders were established, genotyping was performed by PCR. Tail tip DNA was amplified with the following primers: GFAP/ tTA sense primer (TCGCTTTCCTCTGAACGCTTCTCG) and GFAP/ tTA antisense primer (TCTGAACGCTGTGACTTGGAGTGTCC); TRE/IFN- $\gamma$ sense primer (CGAATTCGAGCTCGGTACCC) and TRE/ IFN- $\gamma$ antisense primer (CCATCCTTTTGCCAGTTCCTCCAG).

Five GFAP/tTA lines were established (line 67, line 78, line 96, line 98, and line 110), and three TRE/IFN- $\gamma$ lines were established (line 136, line 184 , and line 215). The founder mice were backcrossed with C57BL/6J mice at least six times. The GFAP/tTA mice were mated with TRE/IFN- $\gamma$ mice to get double transgenic mice.

Line 67 GFAP/tTA mice and line 184 TRE/IFN- $\gamma$ mice on the C57BL/6 background were mated with STAT1 mutant mice (strain 129S6/SvEv$S T A T 1^{t m 1}$; kindly provided by Dr. H. Schreiber, The University of Chicago, Chicago, IL) (Meraz et al., 1996) to obtain GFAP/tTA;STAT1 ${ }^{+/-}$ and TRE/IFN- $\gamma ; S T A T 1^{+/-}$mice. These mice were crossed to obtain GFAP/tTA;TRE/IFN- $\gamma ; \mathrm{STAT1}^{-/-}$mice.

To prevent transcriptional activation of the TRE/IFN- $\gamma$ transgene by tTA, $0.05 \mathrm{mg} / \mathrm{ml}$ doxycycline was added to the drinking water and provided ad libitum.

All animal procedures were conducted in complete compliance with the National Institutes of Health Guide for the Care and Use of Laboratory Animals and were approved by the Institutional Animal Care and Use Committee of The University of Chicago.

$\beta$-Galactosidase histochemistry. Anesthetized mice were perfused with $1 \%$ paraformaldehyde and $0.5 \%$ glutaraldehyde in PBS. The brain was postfixed in $1 \%$ paraformaldehyde and $0.5 \%$ glutaraldehyde for $1 \mathrm{hr}$, then cryopreserved in $30 \%$ sucrose, embedded in optimal cutting temperature (OCT) compound, and frozen on dry ice. Ten-micrometer sections were cut with a cryostat and incubated overnight in $1 \mathrm{mg} / \mathrm{ml}$ 5 -bromo-4-chloro-3-indolyl- $\beta$-D-galactopyranoside (Sigma, St. Louis, MO), $5 \mathrm{~mm}$ potassium ferricyanide, $5 \mathrm{~mm}$ potassium ferrocyanide, $2 \mathrm{~mm}$ $\mathrm{MgCl}_{2}, 0.02 \% \mathrm{NP}-40$, and $0.01 \%$ sodium deoxycholate in PBS at $37^{\circ} \mathrm{C}$ (Doerflinger et al., 2003). The sections were rinsed with PBS, dehydrated in ethanol (70, 80, 95, and 100\%), cleared in xylene, and mounted with Permount.

ELISA. Whole brains were removed, rinsed in ice-cold PBS, and immediately homogenized in 5 vol of PBS with Complete protease mixture (Roche, Indianapolis, IN) using a motorized homogenizer. After incubation on ice for $5 \mathrm{~min}$, the extracts were cleared by centrifugation at 14,000 rpm for $10 \mathrm{~min}$. The protein content of each extract was determined by the DC protein assay (Bio-Rad, Hercules, CA). ELISAs were performed using the Mouse IFN- $\gamma$ Quantikine ELISA kit (R \& D Systems, Minneapolis, MN) according to the manufacturer's instructions.

Histology, immunohistochemistry, and terminal deoxynucleotidyl transferase-mediated biotinylated UTP nick end labeling staining. Anesthetized mice were perfused through the left cardiac ventricle with $4 \%$ paraformaldehyde in $0.1 \mathrm{M}$ phosphate buffer. The brain was bisected in the sagittal plane, and one-half was postfixed for at least $48 \mathrm{hr}$ in $4 \%$ paraformaldehyde in PBS, dehydrated through graded alcohols, and embedded in paraffin. Sections of $5 \mu \mathrm{m}$ thickness were cut and routinely stained with hematoxylin and eosin. The other half of the brain was postfixed for $1 \mathrm{hr}$ in $4 \%$ paraformaldehyde in PBS, cryopreserved in 30\% sucrose, embedded in OCT compound, and frozen on dry ice. Frozen sections were cut in a cryostat at $10 \mu \mathrm{m}$ thickness.

Immunohistochemstry for GFAP (1:1000; Sternberger Monoclonals, Lutherville, MD), synaptophysin (1:200; Chemicon, Temecula, CA), proliferating cell nuclear antigen (PCNA; 1:50; Santa Cruz Biotechnology, Santa Cruz, CA), MAC-1 (integrin $\alpha \mathrm{M}$, a microglial-macrophage marker; 1:50; Chemicon), and cluster of differentiation 3 (CD3; 1:50; Santa Cruz Biotechnology) were performed on paraffin sections. Primary antibodies were detected using the Vectastain $\mathrm{ABC}$ kits (Vector Laboratories, Burlingame, CA) and 3',5'-diaminobenzidine $/ \mathrm{H}_{2} \mathrm{O}_{2}$ reagent as substrate. The sections were counterstained with hematoxylin, dehydrated in ethanol (70, 80, 95, and 100\%), cleared in xylene, and mounted with Permount. Immunofluorescent labeling for the mouse atonal homolog MATH1 (1:50; Chemicon), SHH (1:10; Santa Cruz Biotechnology), and neuron-specific nuclear protein (NeuN; 1:50; Chemicon), was performed on cryosections. Fluorescein-labeled secondary antibodies (Vector Laboratories) were used to detect the mouse atonal homolog MATH1, SHH, and NeuN. The sections were mounted with Vectashield mounting medium with 4',6-diamidino-2-phenylindole (DAPI; Vector Laboratories). We quantified immunopositive cells for PCNA and CD3 by staining every 10th section and counting positive cells in a $0.5 \mathrm{~mm}^{2}$ region of the center of the tumor. A minimum of three sections were analyzed per experimental animal.

Terminal deoxynucleotidyl transferase-mediated biotinylated UTP nick end labeling (TUNEL) staining was performed using the ApopTag kit (Serologicals, Norcross, CA) according to the manufacturer's instructions. The sections were mounted with Vectashield mounting medium with DAPI.

Mice received intraperitoneal injections of $100 \mathrm{mg} / \mathrm{kg}$ bromodeoxyuridine (BrdU; Sigma) $4 \mathrm{hr}$ before perfusion. The sections were treated with $2 \mathrm{M} \mathrm{HCl}$ for $30 \mathrm{~min}$ and neutralized by $0.1 \mathrm{M}$ borate buffer, $\mathrm{pH} 8.5$, for $20 \mathrm{~min}$, then incubated overnight with a monoclonal antiBrdU conjugated to FITC (1:10; Roche). The sections were mounted with Vectashield mounting medium with DAPI.

Fluorescent-stained sections were visualized with an Axioplan fluorescence microscope (Zeiss, Thornwood, NY). Images were captured using a Photometrics PXL CCD camera connected to an Apple Macintosh computer using the Open Lab software suite.

Real-time PCR. RNA was isolated using Trizol reagent (Invitrogen, Carlsbad, CA) and treated with DNAseI (Invitrogen) to eliminate genomic DNA. Reverse transcription (RT) was performed using the Superscript First Strand Synthesis System for RT-PCR kit (Invitrogen). 
Real-time PCR was performed with iQ Supermix (Bio-Rad) on an iQ Real-Time PCR Detection system (Bio-Rad). The primers and probes (Integrated DNA Technologies, Coralville, IA) for real-time PCR were as follows: glyceraldehyde-3-phosphate dehydrogenase (GAPDH) sense primer, CTCAACTACATG-GTCTACATGTTCCA; GAPDH antisense primer, CCATTCTCGGCCTTGACTGT; GAPDH probe, TexRedTGACTCCACTCACGGC-AAATTCAACG-BHQ2; IFN- $\gamma$ sense primer, GATATCTCGAGGAACTGGCAAAA; IFN- $\gamma$ antisense primer, CTTCAAAGAGTCTGAGGTAGAAAGAGATAAT; IFN- $\gamma$ probe, FAM-TGGTGACATGAAAATCCTGCAGAGCCA-BHQ1; major histocompatiblity complex (MHC)-I sense primer, ATTCCCCAAAGGCCCATGT; MHC-I antisense primer, GTCTCCACAAGCTCCATGTCC; MHC-I probe, FAMTGCTGGGCCCTGGGCTTCTACC-BHQ1; MATH1 sense primer, TGCAGACTCCCAATGTCGGA; MATH1 antisense primer, GTGCGAAGGTGATGGTGGTC; MATH1 probe, FAM-CAACCGCCGCCGCCCACAGCBHQ1; SHH sense primer, TTCATAGTAGACCCA-GTCGAAACC; SHH antisense primer, GAGGACGGCCATCATTCAGAG; SHH probe, FAMCTTCCACAGCCAGGCGAGCCAGC-BHQ1; Glil sense primer, TCTCAAACTGCCCAGCTTAAC; Glil antisense primer, CCTGCGGCTGACTGTGTAAG; Gli1 probe, FAM-CGCACCTGTGTCTCGCCGTCTGG-BHQ1; inducible nitric oxide synthase (iNOs) sense primer, GCTGGGCTGTACAAACCTTCC; iNOs antisense primer, TTGAGGTCTAAAGGCTCCGG; iNOs probe, FAM-TGTCCGAAGCAAACATCACATTCAGATCC-BHQ1; tumor necrosis factor- $\alpha$ (TNF- $\alpha$ ) sense primer, GGCAGGTTCTGTCCCTTTCA; TNF- $\alpha$ antisense primer, ACCGCCTGGAGTTCTGGAA; TNF- $\alpha$ probe, FAM-CCCAAGGCGCCACATCTCCCT-BHQ1; IFN- $\gamma$-inducible transcription factor 1 (IRF-1) sense primer: ACCTACAGGTGTCACCCATGC; IRF-1 antisense primer, GCTGCCACTCAGACTGTTCAAA; IRF-1 probe, FAM-CCACCTCCGAAGCCGCAACAGACG-BHQ1; IFN- $\gamma$-inducible protein 10 (IP-10) sense primer, AGGGCCATAGGGAAGCTTGAAA; IP-10 antisense primer, CGGATTCAGACATCTCTGCTCATC; IP-10 probe, FAM-CCCTGCGAGCCTATCCTGCCCACG-BHQ1.

Statistics. Data are expressed as mean \pm SEM. Multiple comparisons were statistically evaluated using a two-tailed Student's $t$ test. Differences were considered statistically significant if $p<0.05$.

\section{Results}

Generation and characterization of double transgenic mice

Five GFAP/tTA transgenic lines were established, each of which was crossed with a TRE/lac Z reporter line provided by Dr. Eric Kandel (College of Physicians and surgeons of Columbia University, New York, NY) (Mayford et al., 1996). In situ enzymatic staining for $\beta$-galactosidase (lac Z) showed numerous blue cells in gray and white matter regions of the cerebellum, forebrain, and spinal cord (Fig. $1 B-D$ ). In the cerebellum, lac $Z$ expression was prominent in the Purkinje cell layer, where it was localized to small cells morphologically consistent with Bergman glia between the large Purkinje neurons. Scattered positive cells were also seen in the cerebellar white matter and granule cell layer. To test whether this transgenic system allowed for controlled expression in the CNS, doxycycline was administered to GFAP/tTA; TRE/lacZ double transgenic mice starting on postnatal day 12 (P12). Six days later, no blue staining cells were found in the CNS of these mice (Fig. 1E), indicating that doxycycline administration had repressed TRE-directed expression of lac $Z$. Furthermore, when GFAP/tTA;TRE/lacZ double transgenic mice were released from doxycycline at 3 weeks of age, induction of lac $Z$ expression could be easily detected in the cerebellum (Fig. $1 F$ ) and throughout the CNS (data not shown) 2 weeks later.

To obtain double transgenic GFAP/tTA;TRE/IFN- $\gamma$ mice with glial-specific expression of IFN- $\gamma$, we crossed line 67 GFAP/tTA mice with line 184 TRE/IFN- $\gamma$ mice. We found that if doxycycline was withheld throughout gestation, $>80 \%$ of the pups died in the neonatal period, and double transgenic pups were never recovered $(n>300)$. This suggested that expression of the IFN- $\gamma$ trans-
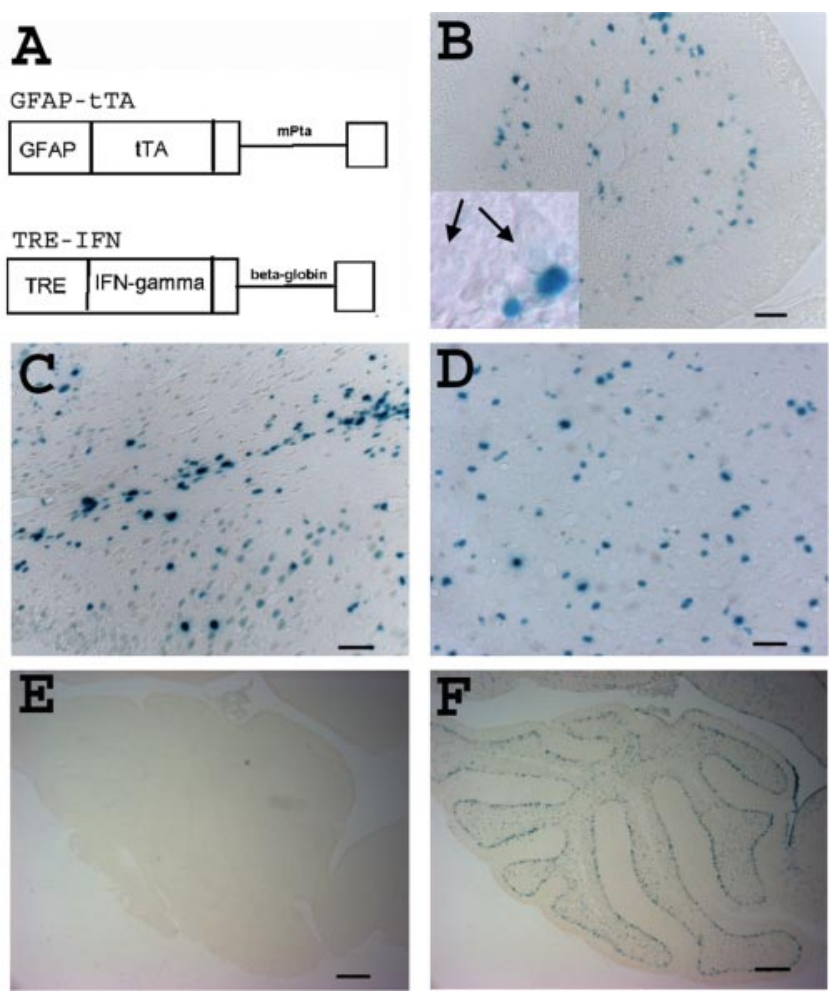

Figure 1. Structure of transgenes and characterization of transgenic mice. $A$, Partial structure of GFAP/tTA and TRE/IFN- $\gamma$ transgenes. B, Cerebellar LacZ staining of P12 GFAP/tTA;TRE/ LacZ double transgenic mice released from doxycycline at E16. Inset, The differential interference contrast photograph shows LacZ-positive cells are not Purkinje cells (arrows). C, Forebrain LacZ staining of P12 GFAP/TTA;TRE/LaCZ double transgenic mice released from doxycycline at E16. D, Spinal cord LaCZ staining of P12 GFAP/tTA;TRE/LacZ double transgenic mice released from doxycycline at E16. E, Cerebellar LacZ staining of P18 GFAP/TTA;TRE/LacZ double transgenic mice released from doxycycline at E16, then retreated with doxycycline at P12. F, Cerebellar LacZ staining of 5-week-old GFAP/TTA;TRE/LacZ double transgenic mice on doxycycline until 3 weeks of age and then released from doxycycline to induce LacZ expression. Scale bars: $B-D, 50 \mu \mathrm{m} ; E, F, 200 \mu \mathrm{m}$.

gene in utero might interfere with embryonic development (Fig. $2 B)$. To circumvent this problem, we administered doxycycline $(0.05 \mathrm{mg} / \mathrm{ml})$ to the breeding pairs according to three regimens: throughout gestation and postnatal development, up until the day of birth (P0), and up until the 16th day of embryonic development (E16). All three treatment regimens allowed the recovery of double transgenic pups in the expected mendelian ratio, and CNS-specific expression of IFN- $\gamma$ could be detected in double transgenic mice released from doxycycline on E16 or on P0 but not in mice maintained on doxycycline (Fig. $2 A, C$ ).

The kinetics of IFN- $\gamma$ expression depended on the timing of the withdrawal of doxycycline (Fig. $2 C, D$ ). In pups released from doxycycline on E16, mRNA for IFN- $\gamma$ and MHC class I (an IFN- $\gamma$ inducible gene) could be detected in the cerebellum as early as P12. ELISA analysis on whole brain at P16 demonstrated IFN- $\gamma$ protein in double transgenic mice released from doxycycline on E16 $(5416 \pm 2668 \mathrm{pg} / \mathrm{mg})$, but IFN- $\gamma$ protein was undetectable in double transgenic mice maintained on doxycycline ( $0 \mathrm{pg} / \mathrm{mg})$. In contrast, the expression of these genes could not be detected until P21 in animals released from doxycycline on P0. The delayed expression of IFN- $\gamma$ in this group of mice is probably related to the build-up of doxycycline stock in the pups and in the mother's milk. A delay in induction of expression after doxycycline withdrawal ranging from several days to many weeks is commonly observed with the tTA/TRE expression system, likely reflecting the half-life of doxycycline in the mouse (Robertson et al., 2002). 

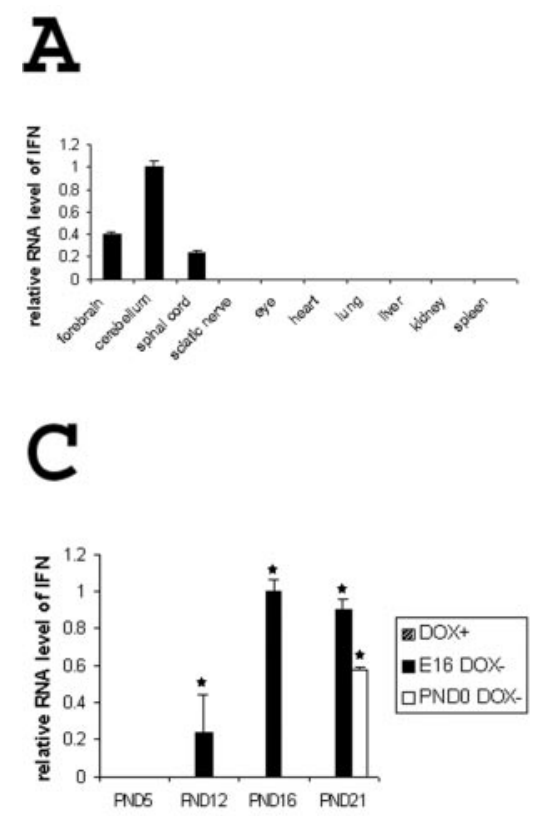

B

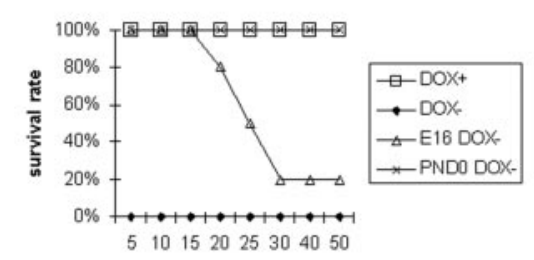

D

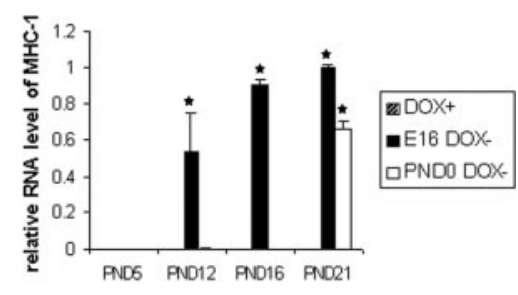

Figure 2. Kinetics of IFN- $\gamma$ expression. $A$, Real-time PCR analysis of the expression pattern of IFN- $\gamma$ in P16 double transgenic mice released from doxycycline on $\mathrm{E} 16(n=3)$. $B$, Survival curve of double transgenic mice ( $n>100$ for each group). $C$, IFN- $\gamma$ real-time PCRanalysis in the cerebellum $(n=3) .{ }^{*} p<0.01$. D, MHC-I real-time PCRanalysis in the cerebellum $(n=3) .{ }^{*} p<0.01$. $\mathrm{DOX}+$, Animals continuously receiving doxycycline; DOX - , animals never receiving doxycycline; E16 D0X - , animals released from doxycycline on E16; PND0 D0X - , animals released from doxycycline on P0.

\section{Early expression of IFN- $\gamma$ leads to medulloblastoma}

Although double transgenic pups maintained on doxycycline or released from doxycycline on P0 appeared healthy with no histological lesions, $\sim 80 \%$ of double transgenic mice ( 87 of 108 ) released from doxycycline on E16 developed a progressive neurological syndrome. Symptoms began in the second postnatal week with growth retardation, followed by tremor and ataxia. All ataxic animals progressed to death at $\sim 3-4$ weeks of age (Fig. $2 B$ ). Necropsy of the ataxic animals invariably revealed infiltrative lesions of the cerebellar hemispheres composed of mitotically active, primitive-appearing cells with hyperchromatic nuclei and scant cytoplasm (Fig. $3 A, C$ ). The tumor cells were involved primarily in the molecular layer and EGL but also frequently invaded the deep cerebellar white matter and adjacent brainstem structures. Extensive cellular proliferation was seen by BrdU labeling and immunohistochemistry for PCNA (see Figs. 3D, 6C). Immunostains showed that many of the neoplastic cells were positive for synaptophysin (Fig. 3E), whereas immunoreactivity for GFAP was mostly confined to processes between the tumor cells (Fig. $3 F$ ). These morphological and immunohistochemical features are very similar to human medulloblastoma (Eberhart and Burger, 2003), and the diffuse involvement of the superficial cerebellar hemisphere suggests an origin from the cells of the EGL. Histological studies of the asymptomatic animals showed no cerebellar abnormalities, and real-time PCR analysis showed variable expression of the IFN- $\gamma$ transgene in these animals (data not shown).

During late embryogenesis, neural precursor cells leave the rhombic lip and stream across the surface of the early cerebellum to form the EGL. At birth, the EGL consists of a single layer of undifferentiated cells. During the next few days, the cells undergo extensive proliferation to generate a large pool of granule cell precursors (GCPs), and then the GCPs begin to differentiate and migrate to their final destination, the internal granule layer (IGL)
(Wechsler-Reya and Scott, 2001; Eberhart, 2003). By P14, EGL cell proliferation normally has ceased and differentiation and migration to the IGL is essentially complete. To determine whether IFN- $\gamma$ is able to induce medulloblastoma after EGL cell proliferation, differentiation, and migration has ceased, we studied double transgenic mice released from doxycycline at birth, in which IFN- $\gamma$ expression can first be detected at approximately P21 (Fig. 2C). The basic structure of the cerebellum in these mice was normal, with no tumor formation or migrational abnormality of the GCPs (Fig. 3B), suggesting that to induce medulloblastoma, IFN- $\gamma$ stimulation must occur before regression of the EGL.

\section{MATH1 activation in IFN- $\boldsymbol{\gamma}$-induced medulloblastoma}

MATH1 is a basic helix-loop-helix transcription factor that is required for the proliferation of GCPs in the EGL (BenArie et al., 1997). MATH1 is specifically expressed in mitotically active precursor cells of the EGL, but its expression is turned off in postmitotic EGL cells and remains off in mature granule cells (Helms and Johnson, 1998). To further determine whether IFN$\gamma$-induced medulloblastoma originated from GCPs present in the EGL, we performed real-time PCR to quantify MATH1 mRNA in the cerebellum of developing mice. As expected, the cerebellum of control mice (double transgenic mice receiving doxycycline, singly transgenic mice, and nontransgenic mice) contained a high level of MATH1 mRNA at P5. MATH1 expression gradually decreased over time so that by P21 little or no MATH1 transcripts could be detected in control mice. Strikingly, the level of MATH1 mRNA remained at a high level in the cerebellum of double transgenic mice released from doxycycline on E16 (Fig. 4A). To further localize the expression of MATH1, we performed MATH1 immunofluorescence and found that tumor cells expressed MATH1 (Fig. 4B,C). Real-time PCR analysis and immunostaining showed that the expression pattern of MATH1 in other regions of the CNS was unchanged in mice expressing IFN- $\gamma$. These data are consistent with neoplastic transformation of the mitotically active MATH1-expressing cells of the EGL.

IFN- $\boldsymbol{\gamma}$-dependent and -independent phases of tumor growth To characterize the progression of medulloblastoma in IFN- $\gamma$ expressing mice, we performed histological studies on P12 (the earliest stage at which affected animals could be reliably identified on clinical grounds because of a mild tremor) and on P16 (when all affected animals showed obvious ataxia). At P12, the lesions were strictly confined to the EGL $(n=5)$, which showed a diffuse hyperplasia throughout the cerebellar hemispheres of affected mice compared with control animals, without extension into the molecular layer and IGL (Fig. 5A,C). By P16, the EGL of control animals had completely regressed (Fig. $5 B$ ), whereas the affected animals $(n=10)$ showed marked proliferation of the EGL with diffuse infiltration of the molecular layer, consistent with a malignant tumor (Fig. 5D).

To test whether the progression of these lesions is dependent 


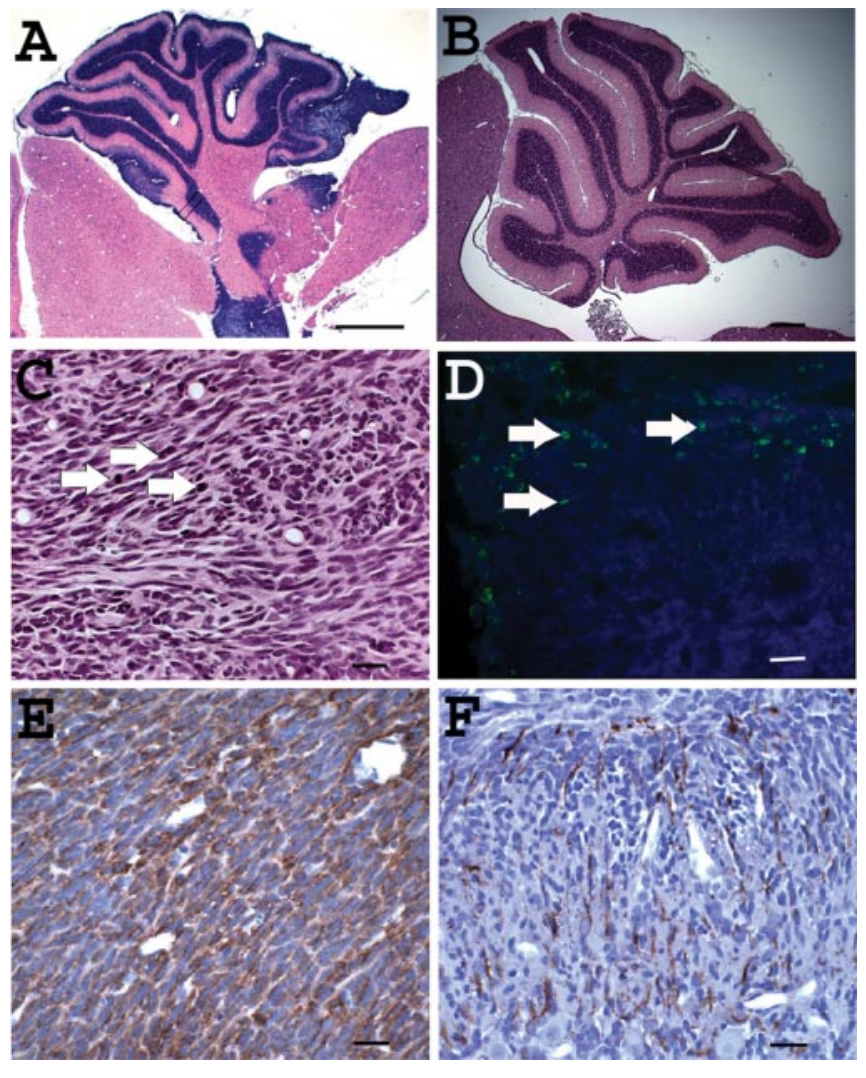

Figure 3. Double transgenic mice released from doxycycline on E16 develop medulloblastoma. A, Low-power magnification of the brain of a P21 double transgenic mouse released from doxycycline on E16 shows a tumor diffusely involving the molecular layer of the cerebellum with multiple foci of extension to the brainstem. $B$, Hematoxylin and eosin staining shows normal cerebellum of P21 double transgenic mouse released from doxycycline at birth. C, High-power magnification shows hypercellular tumor consisting of densely packed cells with hyperchromatic nuclei and mitotic activity (arrows). D, Many proliferating cells in the tumor are revealed with BrdU labeling (arrows; green fluorescence), with weak blue fluorescence showing DAPI counterstain. E, Immunostaining shows that many tumor cells are positive for synaptophysin. $F_{,}$ Immunoreactivity for GFAP is mostly confined to cell processes between tumor cells. Scale bars: A, $1000 \mu \mathrm{m} ; B, 200 \mu \mathrm{m} ; C, E, F, 25 \mu \mathrm{m} ; D, 50 \mu \mathrm{m}$.

on continued expression of IFN- $\gamma$, double transgenic mice that had been released from doxycycline on E16 were treated with doxycycline starting on P12, when they had already developed a minor tremor $(n=9)$. Real-time PCR analysis showed no IFN- $\gamma$ expression in the cerebellum of such animals at P16 $(n=3)$. Clinically, the phenotype of the doxycycline-treated mice improved gradually, and by P28 they were indistinguishable from littermate controls. Necropsy of three mice at P21 showed no evidence of tumor in two of the mice, and a small hyperplastic lesion was confined to the molecular layer in one mouse. Necropsy of three mice at P28 showed no evidence of tumor (Fig. 5E). These data demonstrate that continued IFN- $\gamma$ expression is required for the early hyperplastic lesions of the EGL to progress to medulloblastoma in this model.

A second group of double transgenic mice that had been released from doxycycline on E16 were placed back on doxycycline starting on P16, when they were already showing obvious ataxia and tremor $(n=15)$. The symptoms of these mice never improved, and they all died between 3 and 4 weeks of age, similar to double transgenic animals that were not treated with doxycycline. Real-time PCR analysis at P21 showed that despite the lack of IFN- $\gamma$ expression in the cerebellum of doxycycline-treated animals $(n=3)$, the level of MATH1 mRNA remained 10 times
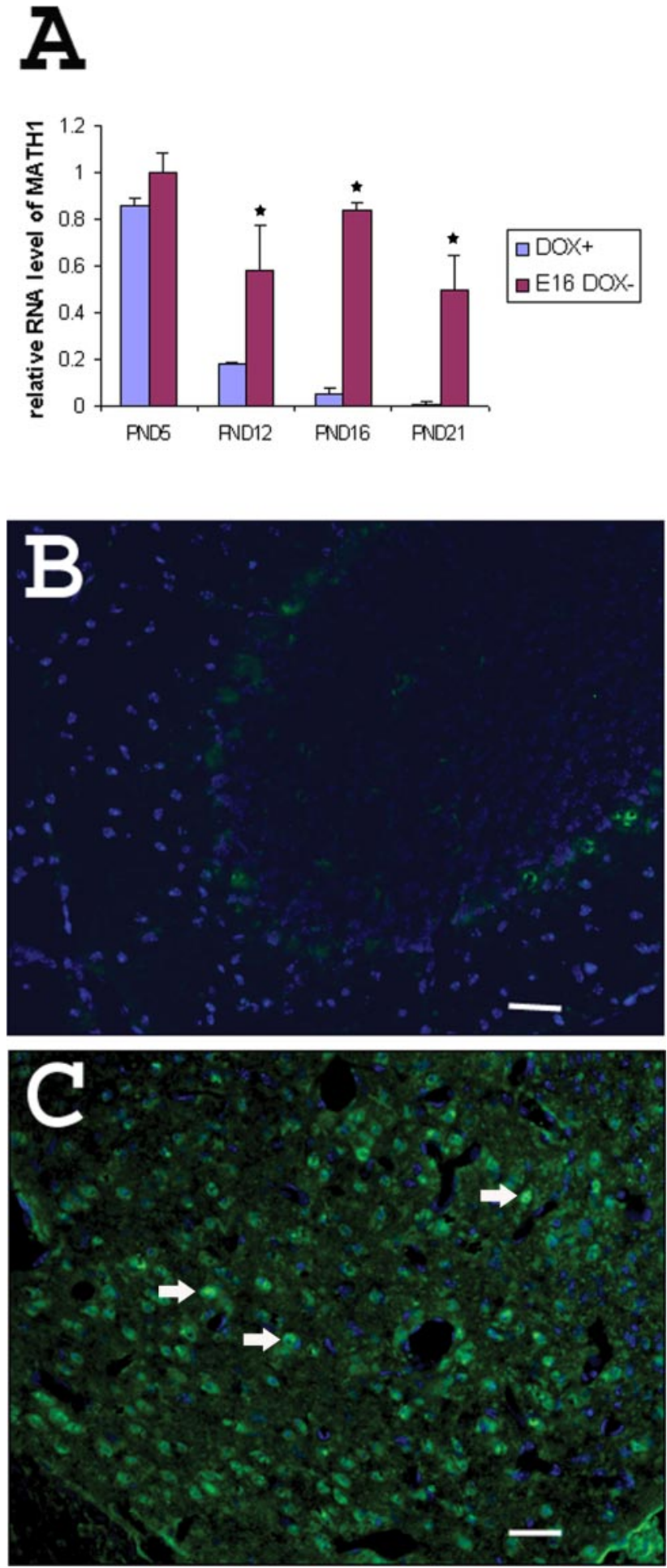

Figure 4. MATH1 activation in medulloblastoma. A, Real-time PCR analysis of MATH1 expression in the cerebellum of double transgenic mice released from doxycycline at $\mathrm{E} 16(n=3)$. ${ }^{*} p<0.01$. B, MATH1 immunostaining in the cerebellum of P21 control mice, with weak blue fluorescence showing DAPI counterstain. C, Tumor cells show a nuclear staining for MATH1 (arrows; green fluorescence), with weak blue fluorescence showing DAPI counterstain. Scale bars: $B, C, 50 \mu \mathrm{m}$.

greater than in normal controls. Necropsy $(n=2)$ at P28 showed the typical histological features of medulloblastoma (Fig. $5 F$ ). Therefore, by P16, repressing expression of the IFN- $\gamma$ transgene with doxycycline is unable to prevent additional progression of medulloblastoma. 

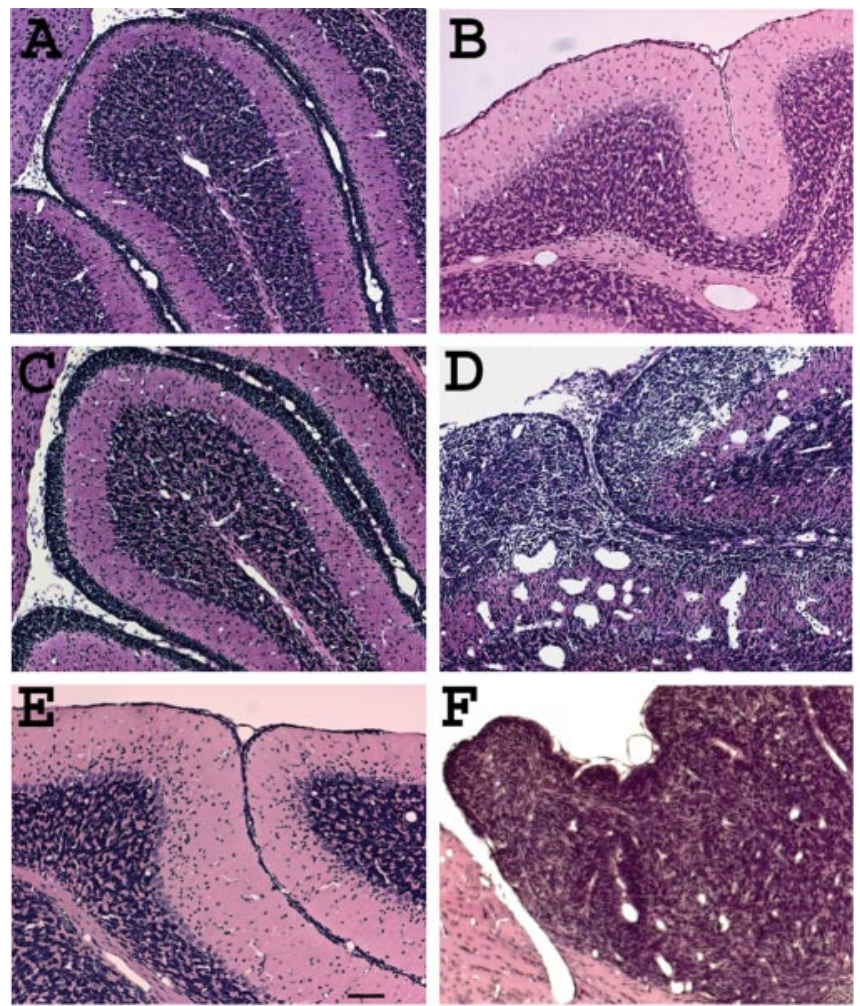

Figure 5. Characterization of IFN- $\gamma$ in medulloblastoma initiation and progression. $A$, The cerebellum of control P12 mice. $B$, The cerebellum of control P16 mice. C, The cerebellum of P12 double transgenic mice released from doxycycline at E16. D, The cerebellum of P16 double transgenic mice released from doxycycline at E16 showing medulloblastoma. E, The cerebellum of $\mathrm{P} 28$ double transgenic mice released from doxycycline at $\mathrm{E} 16$ and then retreated with doxycycline at P12. F, Medulloblastoma remains in the CNS of P28 double transgenic mice released from doxycycline at E16 and then retreated with doxycycline at P16. Scale bar, $75 \mu \mathrm{m}$.

Host response in the presence of IFN- $\gamma$

Several lines of evidence have shown that IFN- $\gamma$ can activate innate and adaptive immune responses against tumors (Kaplan et al., 1998; Shankaran et al., 2001; Ikeda et al., 2002). To determine whether expression of the IFN- $\gamma$ transgene can promote host responses to medulloblastoma, we compared tumors from mice released from doxycycline at E16 with those present in animals that were placed back on doxycycline on P16. We found that the tumors present in animals in which the IFN- $\gamma$ transgene had been repressed showed much less necrosis and apoptosis than tumors in animals with continued expression of the IFN- $\gamma$ transgene (Fig. 6A, $B, E, F$ ). Nevertheless, PCNA immunostaining revealed that there were also significantly more mitotic cells in the tumors of the mice overexpressing IFN- $\gamma$ than the mice without IFN- $\gamma$ expression (Figs. 6C,D, 7A). At the same time, immunohistochemistry revealed that the presence of IFN- $\gamma$ was able to strongly activate MAC-1-positive microglia/macrophages (Fig. 6G,H) and recruit CD3-positive T-cells (Figs. 6I, J, 7A) into the tumors. Furthermore, real-time PCR analysis revealed significantly increased mRNA levels for TNF- $\alpha$ and iNOs in the cerebellum of mice that did not receive doxycycline postnatally (Fig. 7B). This increased response may reflect a direct effect of IFN- $\gamma$ on the immune system, or it may suggest an increased reaction to the more aggressive phenotype of the tumor.

\section{IFN- $\gamma$ induces $\mathrm{SHH}$ expression in medulloblastoma}

The $\mathrm{SHH}$ signaling pathway plays a critical role in normal cerebellar development and in medulloblastoma formation (Ho and
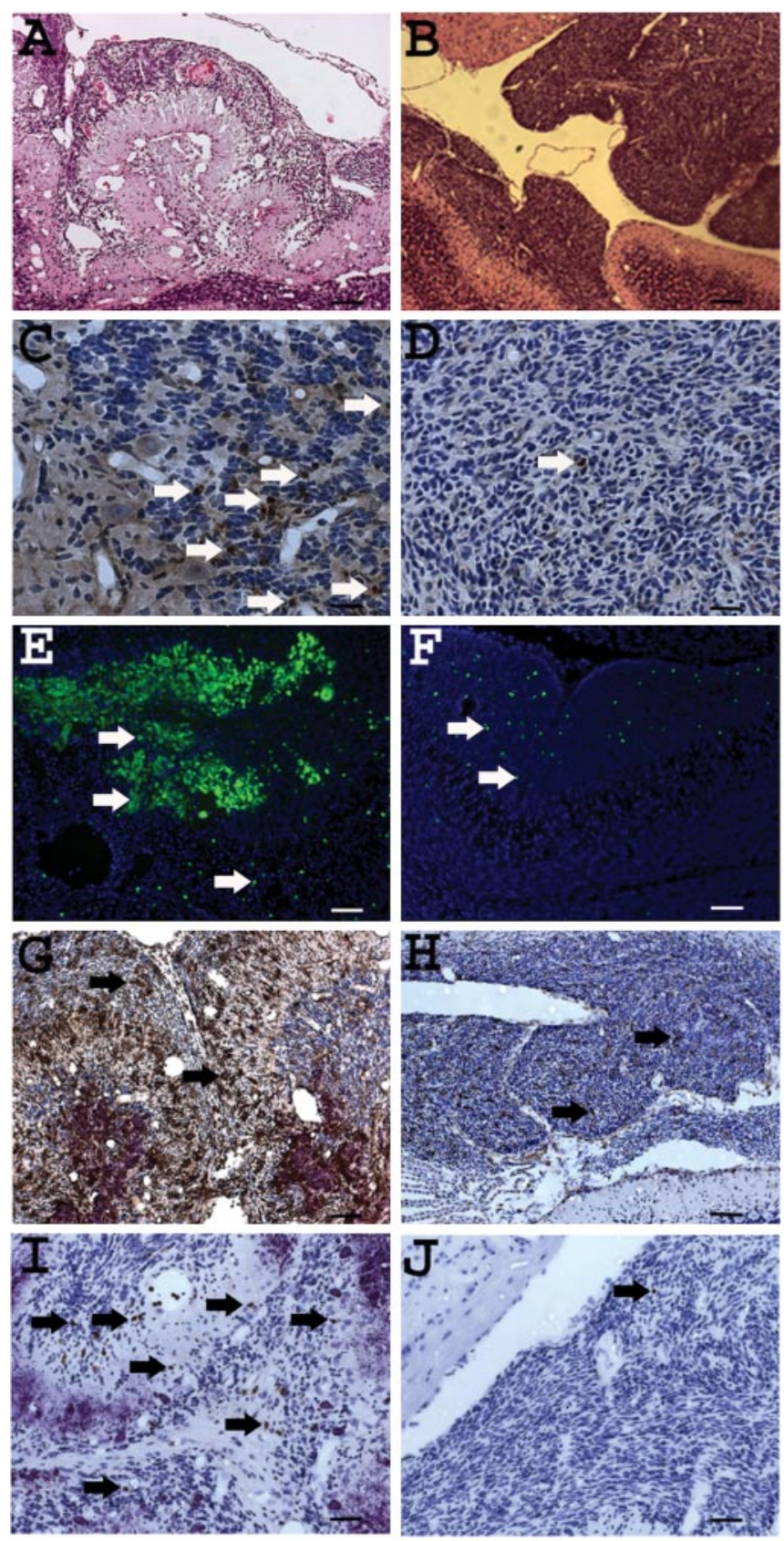

Figure 6. Host reponse in the presence of IFN- $\gamma \cdot A, C, E, G, I$, Tumors from double transgenic animals released from doxycycline on $E 16 . B, D, F, H, J$, Tumors from double transgenic animals released from doxycycline on $\mathrm{E} 16$ and then retreated with doxycyline on P16 to repress expression of the IFN- $\gamma$ transgene. $A, B$, Hematoxylin and eosin staining shows extensive necrosis in the tumors of mice with continued expression of IFN- $\gamma$. C, D, PCNA immunostaining shows many more proliferating cells (arrows) in the tumors of mice with continued expression of IFN- $\gamma$. $E$, $F$, TUNEL staining shows numerous dying cells (arrows; green fluorescence) in the tumors of mice with continued expression of IFN- $\gamma$, with weak blue fluorescence showing DAPI counterstain. $G, H, M A C-1$ immunostaining reveals larger numbers of microglia/macrophages (arrows) infiltrating the tumors of mice with continued expression of IFN- $\gamma$. I, J, CD3 immunostaining reveals numerous $\mathrm{CD}^{+}$T-cells (arrows) infiltrating the tumor of mice with continued expression of IFN- $\gamma$. Scale bars: $A, B, E-H, 75 \mu \mathrm{m} ; C, D, 25 \mu \mathrm{m} ; I, J, 50 \mu \mathrm{m}$.

Scott, 2002; Ruiz i Altaba et al., 2002). Overexpression of SHH is sufficient to induce medulloblastoma during development, and pharmacological blockade of the SHH signaling pathway is able to inhibit medulloblastoma growth in an animal model (Berman et al., 2002; Weiner et al., 2002). Therefore, we were interested in the potential role of the $\mathrm{SHH}$ signaling pathway in IFN- $\gamma$ induced 


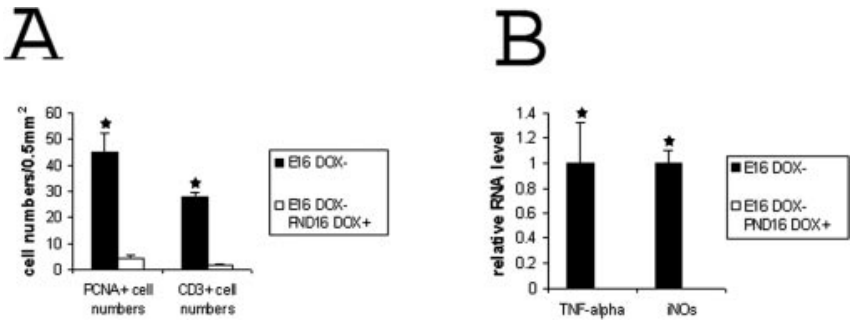

Figure 7. Host reponse in the presence of IFN- $\gamma$. A, Quantitiation of PCNA-positive and CD3-positive cells in the tumors $(n=2) .{ }^{*} p<0.01$. B, Real-time PCR analysis of TNF- $\alpha$ and iNOs mRNA in tumors at P21 $(n=3) .{ }^{*} p<0.01$.

medulloblastoma. Real-time PCR analysis of SHH mRNA showed a dramatic induction of SHH mRNA in the cerebellum of double transgenic mice released from doxycycline on E16. Elevated $\mathrm{SHH}$ expression was first detected on P12 and became more pronounced on P16 and P21 (Fig. 8A). RNase protection assays showed similar results (data not shown). SHH immunohistochemistry revealed $\mathrm{SHH}$ expression in a diffuse manner throughout the tumor mass in P21 mice (Fig. $8 B, C$ ). We also examined expression of Gli1, a transcription factor that is induced by $\mathrm{SHH}$ signaling. Real-time PCR analysis showed that, like $\mathrm{SHH}$, the level of Gli1 mRNA was significantly upregulated during tumorigenesis (Fig. 8D). These data suggest that the $\mathrm{SHH}$ signaling pathway plays an important role in tumorigenesis induced by IFN $-\gamma$.

\section{IFN- $\gamma$-induced medulloblastoma is dependent on STAT1 signaling}

Many of the cellular actions of IFN- $\gamma$ result from its activation of the transcription factor STAT1, and in several cellular contexts, the absence of STAT1 has been shown to convert IFN- $\gamma$ from a cytostatic antiproliferative agent to a mitogen (Bromberg, 2002; Levy and Darnell, 2002; Ramana et al., 2002). Therefore, we were interested in whether the tumorigenic properties of IFN- $\gamma$ in the cerebellum were STAT1 dependent. The GFAP/ tTA and TRE/IFN- $\gamma$ mice were crossed to the $129 S 6 / S v E v$-Stat $1^{\text {tm }}$ strain, which lacks STAT1 activity, and the resulting progeny were intercrossed to obtain double transgenic mice that were homozygous for the STAT1 mutation. No GFAP/tTA;TRE/ $I F N-\gamma$ double transgenic mice were recovered on the STAT1 null background $(n>$ $100)$ if the breeding pairs never received doxycycline, suggesting that the embryonic lethality of IFN- $\gamma$ expression persisted in the absence of STAT1. When such crosses were released from doxycycline at E16, 90\% of double transgenic mice (18 of 20) that were wild type for STAT1 developed medulloblastoma and died by P21. In contrast, littermates $(n=20)$ that were double transgenic and STAT $1^{-1-}$ showed a much milder phenotype. At 2 weeks of age, these animals showed a minor ataxia and tremor, but they all survived at least 8 weeks (Fig. 9A). Real-time PCR analysis showed that the induction of MHC-I expression was reduced relative to that seen in STAT $1^{+/+}$animals and IFN- $\gamma$ expression led to a modest increase in MHC-I mRNA in the CNS of STAT $1^{-1-}$ mice released from doxycycline at E16, whereas the upregulation of the STAT1-dependent, IFN- $\gamma$-responsive genes $I R F-1$ and $I P-10$ was abolished (Fig. 9B). Necropsy showed no tumor formation in the cerebellum of adult double transgenic STAT $1^{-1-}$ mice, but foci of well differentiated granule cells were found near the surface of the molecular layer of the cerebellum in two of eight mice (Fig. $9 C-E)$. These foci of heterotopic neurons were strongly positive for NeuN (Fig. 9F). Moreover, real-time PCR analysis showed no increase in expression of $\mathrm{SHH}$, Gli1, or MATH1 in the cerebellum of GFAP/tTA;TRE/IFN- $\gamma ; S T A T^{-/-}$mice released from doxycycline at E16 (Fig. 9B). Together, these data indicate that the STAT1 signaling pathway is required for maximal induction of IFN- $\gamma$-responsive genes and for tumorigenesis but that STAT1independent signaling pathways also play an important role in an IFN- $\gamma$-mediated disruption of granule cell migration.

\section{Discussion}

The present study shows that the ectopic expression of IFN- $\gamma$ in the CNS during development results in the formation of cerebellar tumors that share the major molecular and pathological characteristics of human medulloblastoma. These features include the time of onset in the developing animals, the location in the corresponding areas of the cerebellum, the highly aggressive behavior of the tumors with typical local infiltration, and the mixed neuronal-glial differentiation pattern. These mice represent a new model for medulloblastoma obtained by the expression of
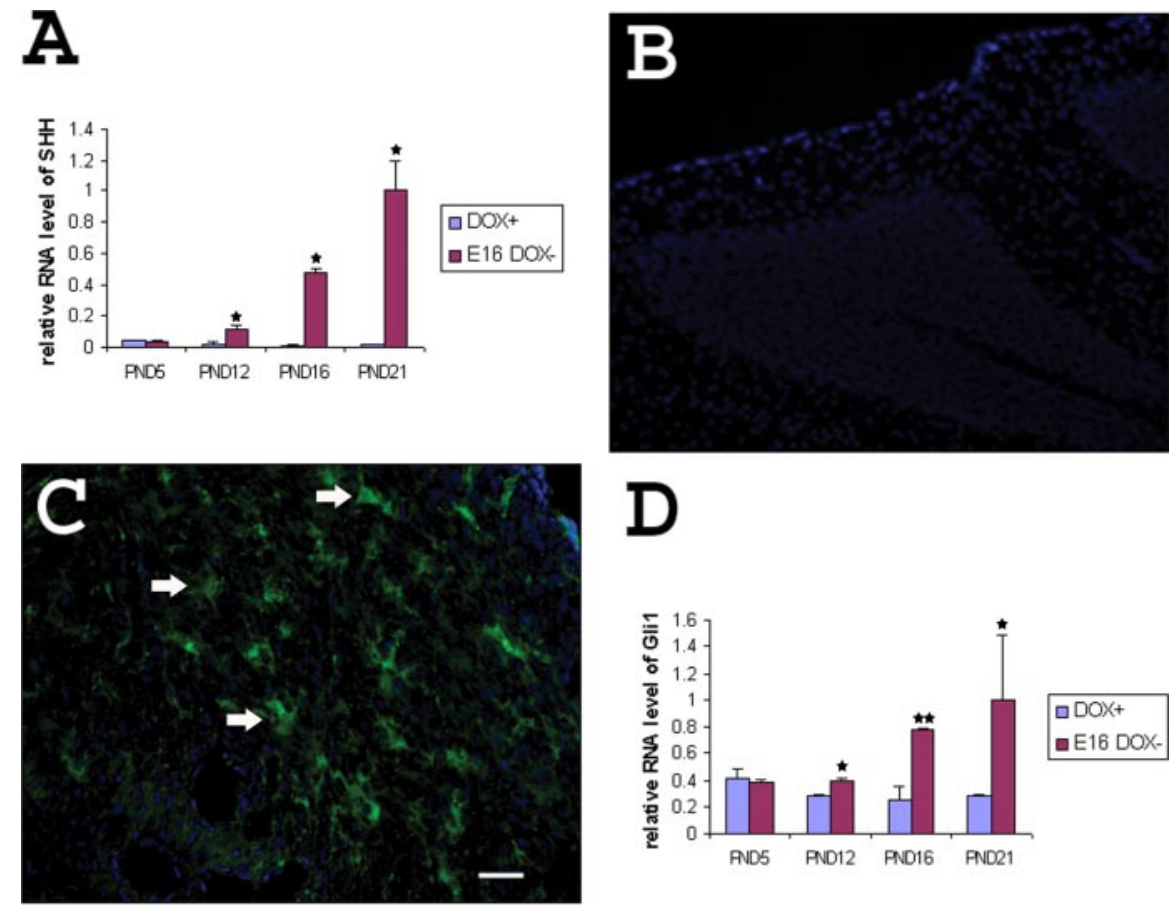

Figure 8. Characterization of SHH signaling in medulloblastoma. A, Real-time PCR analysis of SHH expression in the cerebellum of double transgenic mice released from doxycycline at $\mathrm{E} 16(n=3) .{ }^{*} p<0.01$. B, SHH immunostaining in the cerebellum of P21 control mice, with weak blue fluorescence showing DAPI counterstain. C, Tumor cells showing diffuse staining for SHH (arrows; green fluorescence), with weak blue fluorescence showing DAPI counterstain. D, Real-time PCR analysis of Gli1 expression in the cerebellum of double transgenic mice released from doxycycline at E16 $(n=3) .{ }^{*} p<0.05{ }^{* *} p<0.01$. Scale bar, $50 \mu \mathrm{m}$. 
A
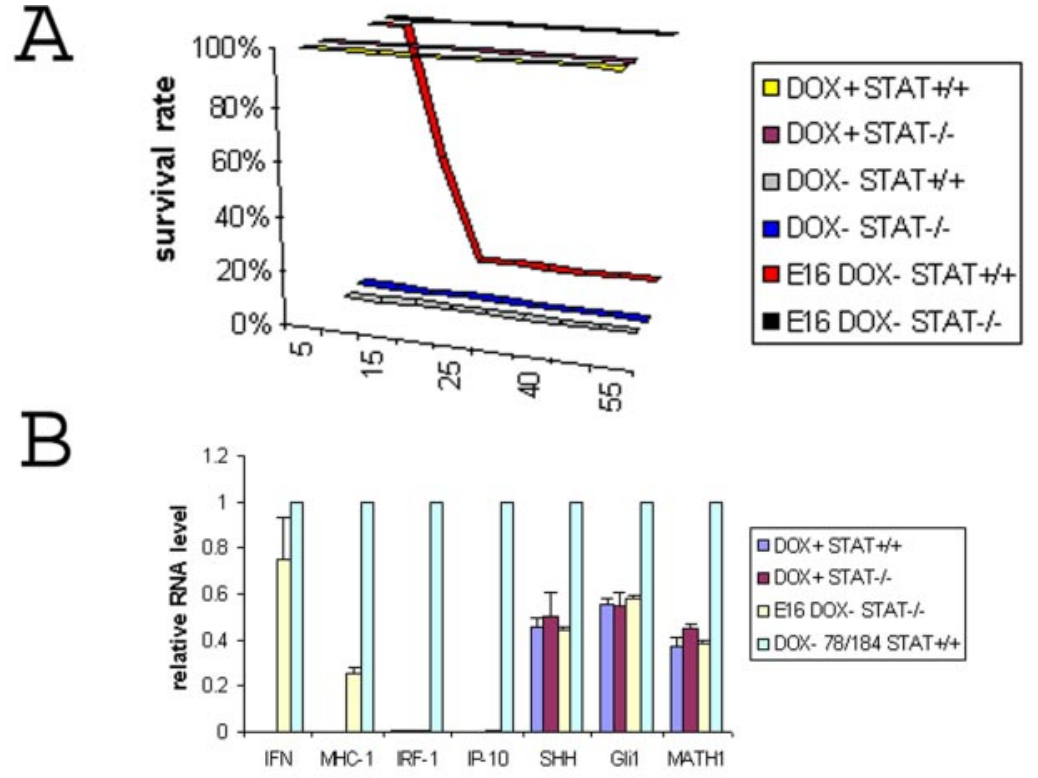

DDOX+STATH+

$\square \mathrm{DOX}+$ STAT $-1-$

口E16 DOX- STAT $\%$

口DOX- 78/184 STAT+1+
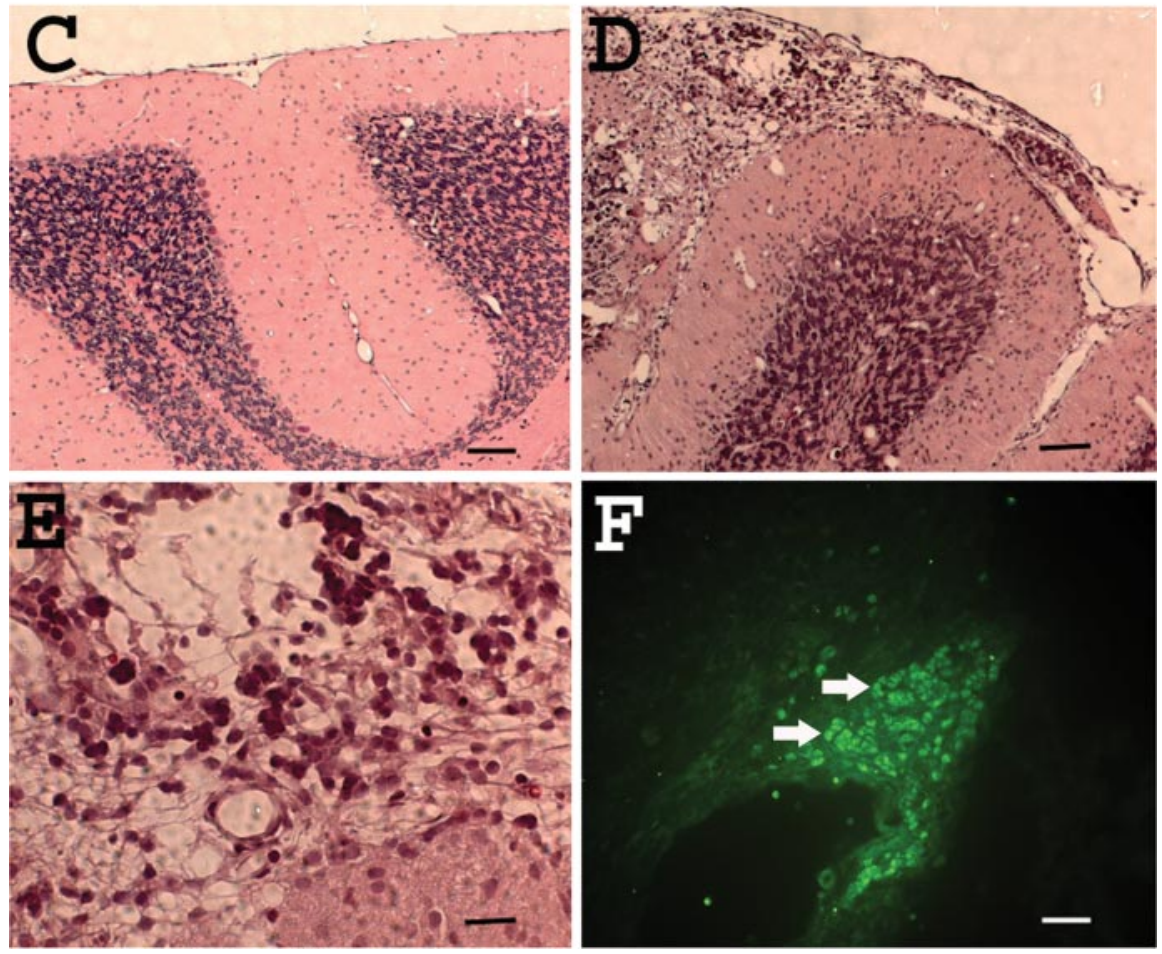

Figure 9. STAT1 dependence of IFN- $\gamma$-induced medulloblastoma. $A$, Survival curve of double transgenic mice on the STAT1 wild-type and STAT1 null background ( $n \geq 20$ for each group). $B$, Real-time PCR analyses of mRNA expression in the cerebellum of 8-week-old mice $(n=3)$. (To obtain double transgenic adults on the STAT1 ${ }^{+/+}$background for comparison, we crossed line 78 GFAP/TTA mice with line 184 TRE/IFN- $\gamma$ mice, a combination with low level IFN- $\gamma$ expression and no medullobastoma.) $C$, The cerebellum of control STAT1 null mice at the age of 8 weeks. D, E, Hematoxylin and eosin staining reveals that some well differentiated granule cells remained near the surface of the molecular layer of cerebellum in double transgenic mice lacking STAT1. F, Immunostaining shows the heterotopic cells were strongly positive for NeuN (arrows; green fluorescence). Scale bars: $C$, $D, 75 \mu \mathrm{m} ; E, F, 25 \mu \mathrm{m}$.

IFN- $\gamma$ in the CNS of transgenic animals and confirm the previously identified potential of IFN- $\gamma$ to cause this developmental tumor (Wang et al., 2003).

Wang et al. (2003) showed that medulloblastoma occurred in STAT2 ${ }^{-1-}$ mice expressing IFN- $\alpha$ under the regulation of a GFAP transcriptional control region. This genetic combination led to an inflammatory process in the developing cerebellum with infiltrating T-lymphocytes expressing IFN- $\gamma$, and it was demonstrated based on in vitro studies that the presence of IFN- $\gamma$ was crucial for $\mathrm{SHH}$ overexpression and medulloblastoma induction. Wang et al. (2003) were unable, however, to separate the relative contributions of the IFN- $\alpha$ expression, IFN- $\gamma$ expression, and STAT2 deficiency to medulloblastoma induction in vivo. We have now shown directly that IFN- $\gamma$ expression in the perinatal cerebellum can lead to $\mathrm{SHH}$ overexpression and medulloblastoma by a STAT1-dependent mechanism.

We show that the cerebellum is sensitive to IFN- $\gamma$-induced medulloblastoma only during a very narrow developmental window. When IFN- $\gamma$ expression is induced by P12, medulloblastoma occurs in $\sim 80 \%$ of the animals. The reason for the lack of tumors in $20 \%$ of these mice has not been determined, but it may reflect animal-to-animal variability in the expression of the IFN- $\gamma$ transgene (data not shown). If IFN- $\gamma$ expression is delayed until P21, no tumors are seen. This developmental window, the predominant localization of the tumor cells in the EGL and molecular layer of the cerebellum, and the strong MATH1 expression by the tumor cells are consistent with an origin from the GCPs, a neural stem cell population that regresses after the second week of postnatal development (Rubin and Rowitch, 2002; Katsetos et al., 2003; Tong et al., 2003). The level of IFN- $\gamma$ expression during this developmental window also appears important for disease severity because other combinations of double transgenic mice with lower levels of IFN- $\gamma$ expression show less severe abnormalities of the cerebellum (Wang et al., 2004). In addition, we find that although IFN- $\gamma$ expression is necessary for induction of medulloblastoma in this model, once the tumors are established, continued expression of IFN- $\gamma$ is not required for tumor progression. Indeed, continued expression of IFN- $\gamma$ seems to induce host responses with extensive macrophage and lymphocytic infiltration and tumor necrosis and apoptosis. Thus, IFN- $\gamma$ expression induces medulloblastoma and promotes innate and adaptive immune cell infiltration of the tumor.

A number of recent studies have reported that viral infection, particularly neurotropic polyomarivus JC virus, may be involved in the development of human neural tumors, including medulloblastoma (Del Valle et al., 2001; Khalili et al., 2003). Interestingly, IFN- $\gamma$ has been demonstrated to be upregulated during the host response to virus infection of the CNS (Weber et al., 2001; Chesler and Reiss, 2002). Together with our data, these human studies suggest that during a critical 
developmental window of GCPs development, IFN- $\gamma$ induction by viral infection of the cerebellum might contribute to medulloblastoma formation.

Several lines of evidence suggest that there are two IFN- $\gamma$ signal transduction pathways: a STAT1-dependent pathway and a STAT1-independent pathway (Ramana et al., 2002). In addition to its critical role in innate and adaptive immunity, STAT1 serves as a potent inhibitor of cell proliferation and promotes apoptosis (Bromberg, 2002; Fulda and Debatin, 2002). Recently, several studies indicated that ablation of the STAT1-dependent signaling pathway can convert IFN- $\gamma$ from a cytostatic antiproliferative agent to a mitogen (Gil et al., 2001; Ramana et al., 2002). In contrast, we find that in our model medulloblastoma formation is dependent on the STAT1 signaling pathway. Given that IFN- $\gamma$ is unable to induce SHH expression in cultured GCPs derived from STAT1 null mice (Wang et al., 2003), it is possible that upregulation of SHH expression by a STAT1-dependent signaling pathway is necessary for IFN- $\gamma$-induced tumorigenesis. Nevertheless, embryonic expression of IFN- $\gamma$ was lethal on the STAT1 null background, suggesting that the harmful effects of IFN- $\gamma$ on prenatal development can occur through STAT1independent signaling pathways. Indeed, IFN- $\gamma$ expression in STAT1 null mice can lead to striking migration abnormalities of cerebellar granule neurons, indicating that the development of this critical cell population is sensitive to STAT1-independent effects of IFN- $\gamma$.

The SHH protein is a secreted glycoprotein that activates a membrane-receptor complex, formed by PTCH and Smoothened (Smo). In the absence of SHH, PTCH binds to Smo and inhibits it, and Gli proteins remain in the transcriptional repression mode. SHH inactivates PTCH, allowing Smo to become active. Active Smo transduces signals that convert Gli proteins into transcriptional activators. SHH is expressed from birth onward in the Purkinje cells of the cerebellum, stimulating the proliferation of GCPs during early postnatal development. Inappropriate $\mathrm{SHH}$ signaling activity, such as from loss-of-function mutations of PTCH in humans and mice or from overexpression of SHH in the mouse brain, are associated with medulloblastoma (Ho and Scott et al., 2002; Ruiz i Altaba, et al., 2002). In this study, induction of medulloblastoma by IFN- $\gamma$ was closely correlated with the upregulation of SHH expression in the cerebellum, suggesting that IFN- $\gamma$ acts via $\mathrm{SHH}$ to induce medulloblastoma. Nevertheless, we find that if IFN- $\gamma$ is repressed after the tumors are established, SHH overexpression is lost (data not shown) and tumor proliferation slows but the medulloblastomas still progress to lethality. Thus, in our model, upregulation of SHH by IFN- $\gamma$ is associated with initiation of medulloblastoma and contributes to the proliferation of established tumors, but it appears unnecessary for the eventual lethal progression of the tumors.

In summary, we have established a transgenic model in which the timing of expression of an IFN- $\gamma$ transgene can be controlled in the CNS. In this model, the expression of IFN- $\gamma$ in a narrow developmental window leads to SHH overexpression and medulloblastoma by a STAT1-dependent mechanism. Once the tumors are established, they become independent of continued IFN- $\gamma$ expression, which promotes innate and adaptive immune responses against the tumors. The high incidence of tumor occurrence and the ability to tightly control the expression of IFN- $\gamma$ should make these mice a particularly useful model to study tumorigenesis and host responses.

\section{References}

Ben-Arie N, Bellen HJ, Armstrong DL, McCall AE, Gordadze PR, Guo Q, Matzuk MM, Zoghbi HY (1997) Math1 is essential for genesis of cerebellar granule neurons. Nature 390:169-172.

Berman DM, Karhadkar SS, Hallahan AR, Pritchard JI, Eberhart CG, Watkins DN, Chen JK, Cooper MK, Taipale J, Olson JM, Beachy PA (2002) Medulloblastoma growth inhibition by hedgehog pathway blockade. Science 297:1559-1561.

Boehm U, Klamp T, Groot M, Howard JC (1997) Cellular responses to interferon-gamma. Annu Rev Immunol 15:749-795.

Brenner M, Kisseberth WC, Su Y, Besnard F, Messing A (1994) GFAP promoter directs astrocyte-specific expression in transgenic mice. J Neurosci 14:1030-1037.

Bromberg J (2002) Stat proteins and oncogenesis. J Clin Invest 109:1139-1142.

Chesler DA, Reiss CS (2002) The role of IFN-gamma in immune responses to viral infections of the central nervous system. Cytokine Growth Factor Rev 13:441-454.

Corbin JG, Kelly D, Rath EM, Baerwald KD, Suzuki K, Popko B (1996) Targeted CNS expression of interferon-gamma in transgenic mice leads to hypomyelination, reactive gliosis, and abnormal cerebellar development. Mol Cell Neurosci 7:354-370.

Del Valle L, Gordon J, Enam S, Delbue S, Croul S, Abraham S, Radhakrishnan S, Assimakopoulou M, Katsetos CD, Khalili K (2001) Expression of human neurotropic polyomavirus JCV late gene product agnoprotein in human medulloblastoma. J Natl Cancer Inst 94:267-273.

Doerflinger NH, Macklin WB, Popko B (2003) Inducible site-specific recombination in myelinating cells. Genesis 35:63-72.

Eberhart CG (2003) Medulloblastoma in mice lacking p53 and PARP: all roads lead to Gli. Am J Pathol 162:7-10.

Eberhart CG, Burger PC (2003) Anaplasia and grading in medulloblastomas. Brain Pathol 13:376-385.

Eng LF, Ghirnikar RS, Lee YL (2000) Glial fibrillary acidic protein: GFAPthirty-one years (1969-2000). Neurochem Res 25:1439-1451.

Fulda S, Debatin KM (2002) IFNgamma sensitizes for apoptosis by upregulating caspase- 8 expression through the Stat1 pathway. Oncogene 21:2295-2308.

Furth PA, St Onge L, Boger H, Gruss P, Gossen M, Kistner A, Bujard H, Hennighausen L (1994) Temporal control of gene expression in transgenic mice by a tetracycline-responsive promoter. Proc Natl Acad Sci USA 91:9302-9306.

Gao X, Kemper A, Popko B (1999) Advanced transgenic and gene-targeting approaches. Neurochem Res 24:1181-1188.

Gil MP, Bohn E, O'Guin AK, Ramana CV, Levine B, Stark GR, Virgin HW, Schreiber RD (2001) Biologic consequences of Stat1-independent IFN signaling. Proc Natl Acad Sci USA 98:6680-6685.

Helms AW, Johnson JE (1998) Progenitors of dorsal commissural interneurons are defined by MATH1 expression. Development 125:919-928.

Ho KS, Scott MP (2002) Sonic hedgehog in the nervous system: functions, modifications and mechanisms. Curr Opin Neurobiol 12:57-63.

Ikeda H, Old LJ, Schreiber RD (2002) The roles of IFN gamma in protection against tumor development and cancer immunoediting. Cytokine Growth Factor Rev 13:95-109.

Kaplan DH, Shankaran V, Dighe AS, Stockert E, Aguet M, Old LJ, Schreiber RD (1998) Demonstration of an interferon gamma-dependent tumor surveillance system in immunocompetent mice. Proc Natl Acad Sci USA 95:7556-7561.

Katsetos CD, Del Valle L, Legido A, de Chadarevian JP, Perentes E, Mork SJ (2003) On the neuronal/neuroblastic nature of medulloblastomas: a tribute to Pio del Rio Hortega and Moises Polak. Acta Neuropathol 105:1-13.

Khalili K, Del Valle L, Otte J, Weaver M, Gordon J (2003) Human neurotropic polyomavirus, JCV, and its role in carcinogenesis. Oncogene 22:5181-5191.

LaFerla FM, Sugarman MC, Lane TE, Leissring MA (2000) Regional hypomyelination and dysplasia in transgenic mice with astrocyte-directed expression of interferon-gamma. J Mol Neurosci 15:45-59.

Levy DE, Darnell Jr JE (2002) Stats: transcriptional control and biological impact. Nat Rev Mol Cell Biol 3:651-662.

Mayford M, Bach ME, Huang YY, Wang L, Hawkins RD, Kandel ER (1996) Control of memory formation through regulated expression of a CaMKII transgene. Science 274:1678-1683. 
Meraz MA, White JM, Sheehan KC, Bach EA, Rodig SJ, Dighe AS, Kaplan DH, Riley JK, Greenlund AC, Campbell D, Carver-Moore K, DuBois RN, Clark R, Aguet M, Schreiber RD (1996) Targeted disruption of the Stat 1 gene in mice reveals unexpected physiologic specificity in the JAK-STAT signaling pathway. Cell 84:431-442.

Packer RJ, Sutton LN, Elterman R, Lange B, Goldwein J, Nicholson HS, Mulne L, Boyett J, D’Angio G, Wechsler-Jentzsch K, Reaman G, Cohen BH, Bruce DA, Rorke LB, Molloy P, Ryan J, Lafond D, Evans AE, Schutt L (1994) Outcome for children with medulloblastoma treated with radiation and cisplatin, CCNU, and vincristine chemotherapy. J Neurosurg 81:690-698.

Popko B, Baerwald KD (1999) Oligodendroglial response to the immune cytokine interferon gamma. Neurochem Res 24:331-338.

Popko B, Corbin JG, Baerwald KD, Dupree J, Garcia AM (1997) The effects of interferon-gamma on the central nervous system. Mol Neurobiol 14:19-35.

Ramana CV, Gil MP, Schreiber RD, Stark GR (2002) Stat1-dependent and -independent pathways in IFN-gamma-dependent signaling. Trends Immunol 23:96-101.

Robertson A, Perea J, Tolmachova T, Thomas PK, Huxley C (2002) Effects of mouse strain, position of integration and tetracycline analogue on the tetracycline conditional system in transgenic mice. Gene 282:65-74.

Rubin JB, Rowitch DH (2002) Medulloblastoma: a problem of developmental biology. Cancer Cell 2:7-8.

Ruiz i Altaba A, Sanchez P, Dahmane N (2002) Gli and hedgehog in cancer: tumours, embryos and stem cells. Nat Rev Cancer 2:361-372.
Shankaran V, Ikeda H, Bruce AT, White JM, Swanson PE, Old LJ, Schreiber RD (2001) IFNgamma and lymphocytes prevent primary tumour development and shape tumour immunogenicity. Nature 410:1107-1111.

Sredni-Kenigsbuch D (2002) TH1/TH2 cytokines in the central nervous system. Int J Neurosci 112:665-703.

Tong WM, Ohgaki H, Huang H, Granier C, Kleihues P, Wang ZQ (2003) Null mutation of DNA strand break-binding molecule poly(ADP-ribose) polymerase causes medulloblastomas in p53 (-/-) mice. Am J Pathol 162:343-352.

Wang J, Pham-Mitchell N, Schindler C, Campbell IL (2003) Dysregulated Sonic hedgehog signaling and medulloblatoma consequent to IFN- $\alpha$ stimulated STAT2-independent production of IFN- $\gamma$ in the brain. J Clin Invest 112:535-543.

Wang J, Lin W, Popko B, Campbell IL (2004) Inducible production of interferon-gamma in the developing brain causes cerebellar dysplasia with activation of the sonic hedgehog pathway. Mol Cell Neurosci, in press.

Weber F, Goldmann C, Kramer M, Kaup FJ, Pickhardt M, Young P, Petry H, Weber T, Luke W (2001) Cellular and humoral immune response in progressive multifocal leukoencephalopathy. Ann Neurol 49:636-642.

Wechsler-Reya R, Scott MP (2001) The developmental biology of brain tumors. Annu Rev Neurosci 24:385-428.

Weiner HL, Bakst R, Hurlbert MS, Ruggiero J, Ahn E, Lee WS, Stephen D, Zagzag D, Joyner AL, Turnbull DH (2002) Induction of medulloblastomas in mice by sonic hedgehog, independent of Gli1. Cancer Res 62:63856389. 